\title{
The risk of tuberculosis transmission in solid organ transplantation: Is it more than a theoretical concern?
}

\author{
Gregory Rose MD
}

\begin{abstract}
G Rose. The risk of tuberculosis transmission in solid organ transplantation: Is it more than a theoretical concern? Can J Infect Dis Med Microbiol 2005;16(5):304-308.

The present case report describes a therapeutic dilemma regarding the transmission of Mycobacterium tuberculosis during transplantation of solid organs, places this phenomenon within the context of the literature, and makes recommendations for screening and therapy.
\end{abstract}

Key Words: Literature review; Microbiology; Organ transplantation; Transmission; Transplants; Tuberculosis

\section{CASE PRESENTATION}

A 48-year-old woman presented with latent tuberculosis (TB) infection (LTBI). At the time, she was considering living unrelated kidney donation to her common-law husband, a 62-yearold man with long-standing chronic renal failure secondary to chronic glomerulonephritis that had progressed to end-stage renal disease.

The patient had a past medical history of breast reduction surgery, various sports injuries, and LTBI initially diagnosed in 1990, when therapy with isoniazid (INH) was initiated but discontinued due to intolerable side effects after one month. She was in excellent health, with no fever, chills, night sweats, weight loss or respiratory symptoms. There were no risk factors for HIV, hepatitis B or hepatitis C, and she was seronegative for all of these viruses. Physical examination was unremarkable, with no lymphadenopathy and a benign chest examination.

Investigations included a single-step tuberculin skin test (TST) yielding an induration of $16 \mathrm{~mm}$ at $48 \mathrm{~h}$, and a chest radiograph demonstrating a right upper lobe calcified nodule in keeping with old granuloma. Because she came from an area endemic for histoplasmosis, the significance of this finding was uncertain.

Because dialysis was an unacceptable therapeutic option for the patient's husband for personal and lifestyle reasons, the couple wished to proceed with kidney transplantation as

\author{
Risque de transmission de la tuberculose \\ durant la transplantation d'un organe plein : \\ Le problème est-il plus que théorique? \\ Le présent rapport de cas décrit un dilemme thérapeutique relatif au \\ risque de transmission de Mycobacterium tuberculosis durant la \\ transplantation d'organes pleins, met ce phénomène en perspective à \\ partir de la littérature publiée sur le sujet et formule des recommandations \\ pour son dépistage et son traitement.
}

swiftly as possible. At first, the patient's history of LTBI was not known to the transplant team, and TSTs were not routinely obtained for donors. The transplantation was planned in three weeks.

The donor, recipient and transplant team wished to know if there was a risk of transmitting TB by renal transplantation and, if so, how to minimize risk so they could proceed with surgery.

\section{METHODS OF REVIEW}

Original papers identifying possible cases of Mycobacterium tuberculosis transmitted by transplantation were identified using a MEDLINE search performed in February 2005 using the following search terms: tuberculosis, tuberculin, infection, transplant, transplantation and graft. Further reports were discovered by searching the bibliographies of identified papers. Restrictions were not placed on date or language of publication. Identified papers were also searched for mention of suspected or proven cases of $\mathrm{TB}$ transmission by solid organ transplantation.

\section{TB POST-TRANSPLANTATION}

The first decade of successful allotransplantation of solid organs showed great improvements in graft preservation, largely by the implementation of immunosuppressant therapy, such as glucocorticoids, azathioprine, radiation, splenectomy and thymectomy $(1,2)$. Transplantation recipients were, however, at high risk for infective illness, including TB. A report from an early transplant

Department of Infectious Diseases, University of Ottawa, Ottawa, Ontario

Correspondence: Dr Gregory Rose, University of Ottawa, 452 Smyth Road, Ottawa, Ontario K1H 8M5. Telephone 613-737-8442,

fax613-737-8164, e-mail grrose@ottawahospital.on.ca

Received for publication April 29, 2005. Accepted May 31, 2005 
centre (2) noted that 65 of 123 recipients $(52.8 \%)$ of solid organ transplantation had died within three years of surgery, with $42(64.6 \%)$ deaths attributed directly to infectious complications. Active TB was discovered in two $(3.1 \%)$ of the 65 patients who died. It has been assumed that the inhibition of cellmediated immunity required for successful allotransplantation (especially by agents such as corticosteroids and azathioprine) is responsible for the increased risk and severity of TB posttransplantation (3).

Over ensuing decades, progress was made in donor-host matching and downward tapering of immunosuppressing regimens, which resulted in improvement in outcomes, but TB remained an uncommon but worrisome complication. In 1983, Lichtenstein and MacGregor (4) reviewed 23 published cases of post-transplantation TB presenting as miliary disease (10 cases [43.5\%]), pulmonary disease (12 cases [52.2\%]) and genitourinary disease (one case [4.3\%]); case mortality was $17.4 \%$ (four of 23 ). This large number of disseminated cases is in contrast with the general population, where $79 \%$ to $84 \%$ of cases are pulmonary (5). Furthermore, Lichtenstein and MacGregor surveyed transplant centres for a retrospective incidence of TB disease post-transplantation, yielding an annual incidence of 480 per 100,000 to 530 per 100,000 recipients, roughly 40 -fold higher than that of the baseline population of the United States. Seven years later, a similar review by Qunibi et al (3) showed an increase in published cases - 44 microbiologically confirmed in all - the majority of which were miliary (28 cases [63.6\%]) or pulmonary (15 cases [34.1\%]) TB. The case mortality was $15.9 \%$ (seven of 44 patients, of whom six had miliary disease). The yearly incidence of $\mathrm{TB}$ in transplantation recipients was 50-fold higher than that of the baseline population of their country, Saudi Arabia.

The largest case review to date (using published cases) identified 511 cases of TB after solid organ transplantation (6). Median time to disease onset post-transplantation was nine months, with nonrenal transplant recipients developing diseases earlier than renal transplant recipients. Similarly, transplant recipients developing early allograft rejection developed TB earlier, as did recipients on tacrolimus alone or a combination of cyclosporine and azathioprine as antirejection regimens. Case mortality was 29\%, with higher mortality in recipients of renal transplants (30\%), those who had developed graft rejection (39\%), those whose TB was miliary $(44 \%)$, and those on muromonab-CD3 or anti-T cell antibodies (60\%) (6). A recent review (7) reported several consistencies in the literature regarding solid organ transplantation: solid organ transplantation recipients are at a 20- to 74-fold increased risk of developing TB; post-transplantation TB is miliary in 33\% of cases; and case mortality approaches 30\% (especially among patients with graft-versus-host disease, or those receiving corticosteroids or antilymphocytic therapy). The review also found a bimodal time to onset post-transplant, at a median of either nine months or over two years (7).

\section{THEORETICAL CONCERNS REGARDING TRANSMISSION OF TB BY SOLID ORGAN TRANSPLANTATION}

Many infectious diseases can be transmitted via solid organs, including viruses (cytomegalovirus, HIV, hepatitis B and C), common bacteria, and more exotic pathogens such as Strongyloides stercoralis and Plasmodium species (8). A common element in these transmissions is that the infection may be disseminated throughout the body; these infections have been demonstrated to be in transplanted organs. M tuberculosis undergoes occult lymphohematogenous dissemination in nonimmune hosts, chiefly seeding the posteroapical segments of the lung (9). Pioneering work by Opie and Aronson in 1927 and Robertson in 1933 demonstrated latent foci of $M$ tuberculosis in a variety of other organs including brain, bone, and especially kidney (10). Asymptomatic renal involvement has been demonstrated even in the course of pulmonary TB (11), so the potential for transmission by solid organs is clear.

\section{PREVIOUS CASES OF TB TRANSMITTED BY SOLID ORGAN TRANSPLANTATION}

A literature search identified 15 possible, probable or proven cases of transmission of $\mathrm{M}$ tuberculosis by solid organ transplantation. The demographics, data regarding the transplantation and immunosuppression, and investigations and risk factors for TB in both the donor and the recipient are summarized in Table 1. Overall, women made up eight $(53.3 \%)$ of the 15 cases, and the median age was 42.5 years (range of one to 63 years of age). Kidney, liver, lung and heart/lung transplantations made up eight $(53.3 \%)$, three $(20 \%)$, three $(20 \%)$ and one $(6.7 \%)$ of the 15 cases, respectively. Only four (26.7\%) of 15 transplants were from living related donors, the rest being cadaveric. For the 11 patients with available data, 10 were on azathioprine regimens for immunosuppression and nine patients were on prednisone.

Among the 15 cases, the evidence for the transmission of TB infection from the transplanted organ varied in strength. Results of TSTs were only reported for two of the four living related donor transplants (patients 1 and 2); in both of these cases, the donor's TST was positive before transplant, with no therapy given for LTBI $(4,9)$. A further two patients (patients 3 and 4) received cadaveric grafts from a donor known to have a negative TST; this TST was performed during the investigation of subacute meningoencephalitis, with abnormal protein, glucose and white blood cells in the cerebrospinal fluid (CSF) (12). This subacute meningoencephalitis was the cause of death of the donor and, three weeks postmortem, CSF cultures grew M tuberculosis. Two weeks later, both patients developed symptoms of demonstrable mycobacteria in the urine requiring subsequent therapy. There were three other pairs of patients who received organs from common donors. In one reported pair, it was the coincident occurrence of tuberculous disease in both recipients that made the reporting physician suspect that the donor was the common source (13), whereas in the other two pairs, the two recipients from each donor were found to have strains of $M$ tuberculosis identical on restriction fragment length polymorphism analysis (14) or heminested inverse polymerase chain reaction (15). There are two reports of TB transmission by organs from living related donors found to have LTBI only after active disease developed in the recipients $(3,16)$. In one of these cases, the donor's pretransplantation chest $\mathrm{x}$-ray was found to be abnormal in retrospect, and her TST (not checked pretransplantation) was strongly positive (16). There is one further well-established case of TB infection from solid organ transplantation, where the cadaveric donor's predeath chest $\mathrm{x}$-rays were found to have apical opacities and mid-lung zone calcifications (17). Unfortunately, this was discovered after the recipient became ill (the $\mathrm{x}$-rays were reported as normal before transplantation). The donor was from Guatemala, a country endemic for TB, and the recipient's $M$ tuberculosis strain matched Guatemalan isolates.

Of note, both Graham et al (15) and Winthrop et al (17) reported that infected donors' organs have been transplanted into 
TABLE 1

Demographics, transplantation data and pretransplantation tuberculosis (TB) status for cases of TB transmitted by solid organ transplantation

\begin{tabular}{|c|c|c|c|c|c|c|c|}
\hline $\begin{array}{l}\text { Year } \\
\text { (reference) }\end{array}$ & Patient & Age/sex & Organ & Donor & $\begin{array}{l}\text { TB status } \\
\text { of donor }\end{array}$ & Recipient TB status & Immunosuppression \\
\hline $1973(10)$ & 1 & $32 / \mathrm{M}$ & Kidney & LR & TST positive, CXR normal & TST negative, CXR normal & Splen; Aza and Pred \\
\hline $1983(4)$ & 2 & $14 / F$ & Kidney & LR & TST positive & TST negative & Aza and Pred \\
\hline $1984(12)$ & 3 & $34 / \mathrm{M}$ & Kidney & $C^{*}$ & $\begin{array}{l}\text { TST negative, CXR unknown, } \\
\text { Mycobacterium tuberculosis } \\
\text { grown } 3 \text { weeks postmortem }\end{array}$ & NR & $\begin{array}{l}\text { Splen; Aza and Pred MP } \\
\text { Rad and ATAb for } \\
\text { rejection }\end{array}$ \\
\hline $1984(12)$ & 4 & $35 / \mathrm{M}$ & Kidney & $\mathrm{C}^{*}$ & $\begin{array}{l}\text { TST negative, CXR unknown, } \\
M \text { tuberculosis grown } 3 \text { weeks } \\
\text { postmortem }\end{array}$ & NR & $\begin{array}{l}\text { Aza and Pred MP, Rad } \\
\text { and ATAb for rejection }\end{array}$ \\
\hline $1985(13)$ & 5 & $46 / F$ & Kidney & $\mathrm{c}^{\dagger}$ & CXR normal, TST unknown & NR & Aza and Pred \\
\hline $1985(13)$ & 6 & $48 / \mathrm{M}$ & Kidney & $\mathrm{C}^{+}$ & CXR normal, TST unknown & NR & ALG, Aza and Pred \\
\hline $1990(18)$ & 7 & $23 / F$ & Heart/Lung & C & NR & TST negative & $\begin{array}{l}\text { Pred, CSA, Aza and } \\
\text { ALAb MP for rejection }\end{array}$ \\
\hline $1990(3)$ & 8 & $\mathrm{NR} / \mathrm{M}$ & Kidney & LR & Post-transplant developed active TB & NR & NR \\
\hline $1996(14)$ & 9 & $42 / F$ & Lung & $C^{\ddagger}$ & $\begin{array}{l}\text { CXR normal, but both recipients } \\
\text { developed the same strain of TB }\end{array}$ & NR & CSA, Pred and Aza \\
\hline $1996(14)$ & 10 & $63 / F$ & Lung & $C^{\ddagger}$ & $\begin{array}{l}\text { CXR normal, but both recipients } \\
\text { developed the same strain of TB }\end{array}$ & NR & CSA, Pred and Aza \\
\hline $1997(16)$ & 11 & $1 / F$ & Liver & LR & Post-transplant developed active TB & NR & Tac and MP \\
\hline $2001(15)$ & 12 & $44 / \mathrm{M}$ & Kidney & $C \S$ & $\begin{array}{l}\text { CXR normal, but both recipients } \\
\text { developed the same strain of TB }\end{array}$ & CXR normal & $\begin{array}{l}\text { Aza, later MMF MP for } \\
\text { rejection }\end{array}$ \\
\hline 2001 (15) & 13 & $61 / F$ & Liver & $C \S$ & $\begin{array}{l}\text { CXR normal, but both recipients } \\
\text { developed the same strain of TB }\end{array}$ & CXR normal & NR; did have rejection \\
\hline 2004 (17) & 14 & $49 / F$ & Lung & C & $\begin{array}{l}\text { CXR: Calcifications and apical opacity; } \\
\text { from endemic area }\end{array}$ & NR & NR \\
\hline $2004(19)$ & 15 & $43 / \mathrm{M}$ & Liver & C & From endemic area & TST negative, CXR normal & NR \\
\hline
\end{tabular}

*Patients 3 and 4 received kidneys from the same cadaveric donor; ${ }^{\dagger} P$ atients 5 and 6 received kidneys from the same cadaveric donor; $¥ P$ atients 9 and 10 received lungs from the same cadaveric donor; §Patients 12 and 13 received organs from the same cadaveric donor. ALAb Antilymphocyte antibody; ALG Antilymphocyte globulin; ATAb Antithymocyte antibody; Aza Azathioprine; C Cadaveric donor; CSA Cyclosporine A; CXR Chest X-ray; F Female; LR Living related donor; M Male; MMF Mycophenolate mofetil; MP Methylprednisolone; NR Not reported; Pred Prednisone; Rad Radiation therapy; Splen Splenectomy; Tac Tacrolimus; TST Tuberculin skin test

other recipients, and that these recipients did not develop tuberculous diseases (Graham reported one other recipient and Winthrop reported three other recipients). Finally, there are two reports of presumed TB transmission via solid organ transplantation based on isolation of the post-transplantation tuberculous disease to the transplanted organs $(18,19)$. A further review of the literature yielded seven papers with a total of 36 cases of TB isolated to the transplanted organ (20-26); of these, only one case did not occur in a country considered endemic for TB (20); therefore, conclusions about the source of the post-transplantation TB cannot be drawn.

\section{OUTCOME OF PATIENTS INFECTED WITH TB FROM SOLID ORGAN TRANSPLANTATION}

Table 2 summarizes the course of the post-transplantation tuberculous disease. The median time to onset of tuberculous disease was three months (range of 0.5 to 38 months). The patient with the shortest onset time was a lung transplantation patient whose postoperative bronchoscopy yielded $M$ tuberculosis; this patient only had radiological evidence of TB with no clinical findings when therapy was initiated (17). Patient 10 was found to have asymptomatic pulmonary TB on bronchoscopy obtained after patient 9 developed disease (14).

The remaining 13 patients all were symptomatic, although these symptoms were often initially subtle or nonspecific, such as fever without other symptoms (13), or fever and cough (18).
This explains the median time of four weeks from symptom onset to initiation of antimycobacterial therapy (range of one to 10 weeks).

Therapy regimens were variable, with treatment times ranging from four to 12 months (patient 1 remained on therapy when this case was published) (10). Rifamycin and INH were included in eight of $11(72.7 \%)$ regimens fully described. Two investigators avoided rifampin for fear of adverse interactions with antirejection medications. Only eight $(53.3 \%)$ of 15 cases recovered from post-transplantation TB with graft function intact. Three (20\%) patients died, and four $(26.7 \%)$ patients had graft failure; of these four patients, two underwent retransplantation and two underwent dialysis.

\section{IMPLICATIONS FOR MONITORING AND TREATMENT}

Screening of recipients and donors

In 1975, Thomas and Manko (27) developed consensus recommendations for screening for LTBI in recipients pretransplantation. Balancing the arguments that TB caused death in four of 10,000 transplantation patients (and likely infected many more), and that anergy to TST was present in $62 \%$ of pretransplant uremic patients (versus the argument that significant INH hepatoxicity occurred in 8.1 of 1000 patients and could theoretically lead to discontinuation of immunomodulating medications), they recommended INH 
TABLE 2

Clinical presentation, therapy and outcome of tuberculosis (TB) transmitted by solid organ transplantation

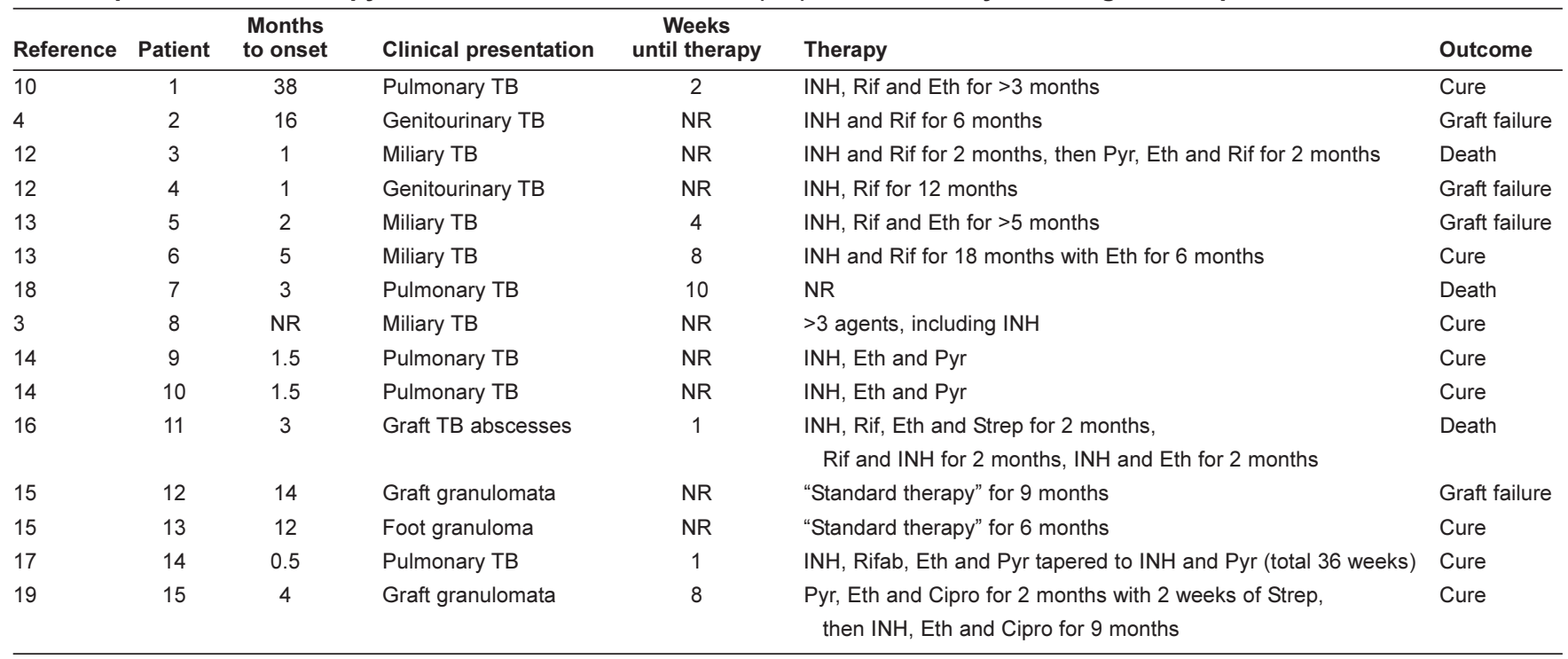

Cipro Ciprofloxacin; Eth Ethambutol; INH Isoniazid; NR Not reported; Pyr Pyrazinamide; Rif Rifampin; Rifab Rifabutin; Strep Streptomycin

for all recipients previously treated for active TB, testing of all recipients with a TST and anergy screen, with treatment of positive TSTs, and close follow-up for all anergic patients (27).

Thirty years later, reviews by Singh and Paterson (6) and Muñoz et al (7) have updated these recommendations, advocating a two-step TST (ie, repeated tests at least one week apart in the event of an initially negative TST), and no anergy screening. Anergy screens do not contribute to identifying false-negative TSTs and are not recommended in recent TB guidelines (28). The recommendation is for INH treatment of LTBI if a TST yields induration of over $5 \mathrm{~mm}$, if there are typical chest $\mathrm{x}$-ray findings, or if there is a history of undertreated TB in either donor or recipient $(6,7)$.

A 1983 survey (4) showed that only 15\% of transplant centres routinely screen living donors, and just over $50 \%$ inquire about the TST status of cadaveric donors. Our centre, 20 years later, does not routinely screen donors. The present review suggests that a positive TST in a potential living donor is indeed a risk for transmission of TB to the recipient. Therefore, it is reasonable that, in addition to screening the recipient with a TST, potential donors should be screened.

Once donors with LTBI are identified, standard therapy for LTBI using INH for nine months or rifampin for six months before transplantation seems reasonable (28). However, in 1992, Krane et al (29) reported a series of six planned living related donors with a TST of $10 \mathrm{~mm}$ or higher, and normal chest radiology treated for three months with $300 \mathrm{mg} /$ day of INH before kidney transplantation into TST-negative recipients. Each of the recipients remained well, TST-negative, and without clinical, radiographic or microbiological evidence of TB during a mean follow-up time of 41.5 months.

Identification and treatment of cases post-transplantation In some situations, pretransplantation screening might not be possible. Certainly, in a situation where a donor has died of an undiagnosed subacute febrile process with purulent CSF (12), pretransplant screening is inappropriate. There may also be situations where culture results are not available until after transplantation, or radiology results are inaccurately reported. When this occurs, there must be an effective, rapid approach to correlate donor clinical information with patient care. A two-week lag between the identification of active TB meningitis in the donor and evaluation of the recipients is excessive (12).

Muñoz et al (7) have suggested that if the donor's LTBI is discovered after transplantation, then the possibility of active TB infection in recipients merits the institution of multidrug antimycobacterial therapy until tuberculous infection can be excluded (usually after seven to eight weeks of culture for mycobacteria), followed by INH therapy for LTBI. Controversy remains with respect to selection of the initial regimen and the duration of INH therapy for LTBI. Muñoz et al specify an initial regimen of INH, ethambutol and pyrazinamide, and suggest avoiding rifampin due to its downregulation of immunosuppressants such as cyclosporin $\mathrm{A}$ and tacrolimus. Rifabutin may be an option for initial antimycobacterial therapy (30).

In transplantation patients, INH is also a controversial drug, causing elevated liver enzymes in $2.5 \%$ to $40 \%$ of recipients post-transplantation (6), particularly in liver transplantation. However, when controlled for other causes of elevated liver enzymes, transplantation recipients are likely not at higher risk for INH toxicity than a baseline population. There seems little reason to extend INH therapy for LTBI past nine months in this population $(6,30)$.

\section{FOLLOW-UP ON THE PRESENT CASE}

It was concluded that there was indeed a risk of our patient transmitting TB with her donated kidney, and that this required intervention. Considering the risks and benefits of treating the donor versus the recipient, it was decided to delay the date of transplantation and start the donor on therapy for LTBI. A six-month course of rifampin was given to expedite surgery and, in consideration of previous INH intolerance, the patient has currently completed three months of 
therapy with no concerns. Her husband has been maintained without dialysis during this time, with close follow-up by the nephrology team, and surgery is planned in three months.

\section{CONCLUSIONS}

There are 15 published cases of possible or probable transmission of TB with solid organ transplantation, with a case mortality of $20 \%$ and a graft failure rate of $26.7 \%$. Potential living donors should be screened with a TST and chest $\mathrm{x}$-rays and treated for latent TB infection if appropriate. This treatment may be truncated to three months of INH therapy before transplantation. The medical records of cadaveric donors should be thoroughly reviewed for radiographic, epidemiological or symptomatic history of probable TB.

\section{REFERENCES}

1. Barry JM. Renal transplantation. In: Walsh PC, Campbell MF, Retik AB, eds. Campbell's Urology. WB Saunders Company, 2002.

2. Hill RB Jr, Dahrling BE II, Starzl TE, Rifkind D. Death after transplantation: An analysis of sixty cases. Am J Med 1967;42:327-34

3. Qunibi WY, al-Sibai MB, Taher S, et al. Mycobacterial infection after renal transplantation - report of 14 cases and review of the literature. Q J Med 1990;77:1039-60.

4. Lichtenstein IH, MacGregor RR. Mycobacterial infections in renal transplant recipients: Report of five cases and review of the literature. Rev Infect Dis 1983;5:216-26.

5. Centers for Disease Control and Prevention. Reported Tuberculosis in the United States, 2003. <http://www.cdc.gov/nchstp/tb/surv/ surv2003/default.htm> (Version current at September 7, 2005).

6. Singh N, Paterson DL. Mycobacterium tuberculosis infection in solidorgan transplant recipients: Impact and implications for management. Clin Infect Dis 1998;27:1266-77.

7. Muñoz P, Rodriguez C, Bouza E. Mycobacterium tuberculosis infection in recipients of solid organ transplants. Clin Infect Dis 2005;40:581-7.

8. Eastlund T. Infectious disease transmission through cell, tissue, and organ transplantation: Reducing the risk through donor selection. Cell Transplant 1995;4:455-77.

9. Haas DW. Mycobacterium tuberculosis. In: Dolin R, Bennett JE, eds. Mandell, Douglas and Bennett's Principles and Practice of Infectious Diseases, 5th edn. Philadelphia: Churchill Livingstone, 2000:2584-85.

10. Lakshiminarayan S, Sahn SA. Tuberculosis in a patient after renal transplantation. Tubercle 1973;54:72-6.

11. Vidal J, Fourcade, Plane. [Silent renal tuberculosis discovered at autopsy]. Montp Med 1950;133:37-38.

12. Peters TG, Reiter CG, Boswell RL. Transmission of tuberculosis by kidney transplantation. Transplantation 1984;38:514-6.

13. Mourad G, Soulillou JP, Chong G, Pouliquen M, Hourmant M, Mion C. Transmission of Mycobacterium tuberculosis with renal allografts. Nephron 1985;41:82-5.

14. Ridgeway AL, Warner GS, Phillips P, et al. Transmission of Mycobacterium tuberculosis to recipients of single lung transplants from the same donor. Am J Respir Crit Care Med 1996;153:1166-8.

15. Graham JC, Kearns AM, Magee JG, et al. Tuberculosis transmitted through transplantation. J Infect 2001;43:251-4.
A rapid response to identify and manage organ transplantation recipients is necessary in the event that a possible infection from the donor is identified. Solid organ transplantation recipients who may have been exposed to TB from donated organs must be immediately investigated for tuberculous disease and empirically started on antimycobacterial therapy with INH, pyrazinamide and ethambutol, with rifabutin at the clinician's discretion until active TB is ruled out. They should then complete INH therapy for latent TB infection.

ACKNOWLEDGEMENTS: The author thanks Dr Gary Garber for his guidance, and the staff of the Ottawa Hospital Medical Library and Dr Ted Eastlund for helping to locate older reports.

16. Kiuchi T, Inomata Y, Uemoto S, et al. A hepatic graft tuberculosis transmitted from a living-related donor. Transplantation 1997;63:905-7.

17. Winthrop KL, Kubak BM, Pegues DA, et al. Transmission of Mycobacterium tuberculosis via lung transplantation. Am J Transplant 2004;4:1529-33.

18. Carlsen SE, Bergin CJ. Reactivation of tuberculosis in a donor lung after transplantation. AJR Am J Roentgenol 1990;154:495-7.

19. Alothman A, Al Abdulkareem A, Al Hemsi B, Issa S, Al Sarraj I, Masoud F. Isolated hepatic tuberculosis in a transplanted liver. Transpl Infect Dis 2004;6:84-6.

20. Walker JF, Cronin CJ, O'Neill S, McNulty J, Hanson JS. Tuberculosis affecting a cadaveric renal allograft. Clin Nephrol $1982 ; 17: 262-5$.

21. Hall CM, Willcox PA, Swanepoel CR, Kahn D, Van Zyl Smit R. Mycobacterial infection in renal transplant recipients. Chest 1994;106:435-9.

22. Lorimer I, Botha J, Pontin AR, Pascoe MD, Kahn D. Tuberculosis isolated to the renal allograft. Transpl Infect Dis 1999;1:83-6.

23. Douie WJ, Halkett J, Botha J, et al. Two further cases of tuberculosis in a renal allograft. Transpl Infect Dis 2000;2:44-5.

24. Dowdy L, Ramgopal M, Hoffman T, et al. Genitourinary tuberculosis after renal transplantation: Report of 3 cases and review. Clin Infect Dis 2001;32:662-6.

25. el-Agroudy AE, Refaie AF, Moussa OM, Ghoneim MA. Tuberculosis in Egyptian kidney transplant recipients: Study of clinical course and outcome. J Nephrol 2003;16:404-11.

26. Lui SL, Tang S, Li FK, et al. Tuberculous infection in southern Chinese renal transplant recipients. Clin Transplant 2004;18:666-71.

27. Thomas PA Jr, Manko MA. Chemoprophylaxis for the prevention of tuberculosis in the immunosuppressed renal allograft recipient. Transplantation 1975;20:76-7.

28. Weir E, Fisman DN. Latent tuberculosis: Revised treatment guidelines. CMAJ 2003;169:937-8.

29. Krane NK, Clark R, Archie M, Tulmulty D, Cunningham D. Use of PPD positive (+) donors in living related kidney donor (LRKD) transplantation. Clin Res 1992;40:797A.

30. EBPG Expert Group on Renal Transplantation. European best practice guidelines for renal transplantation. Section IV: Long-term management of the transplant recipient. IV.7.2. Late infections. Tuberculosis. Nephrol Dial Transplant 2002;17(Suppl 4):39-43. 


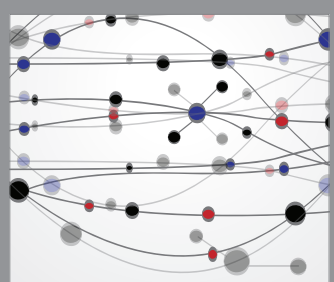

The Scientific World Journal
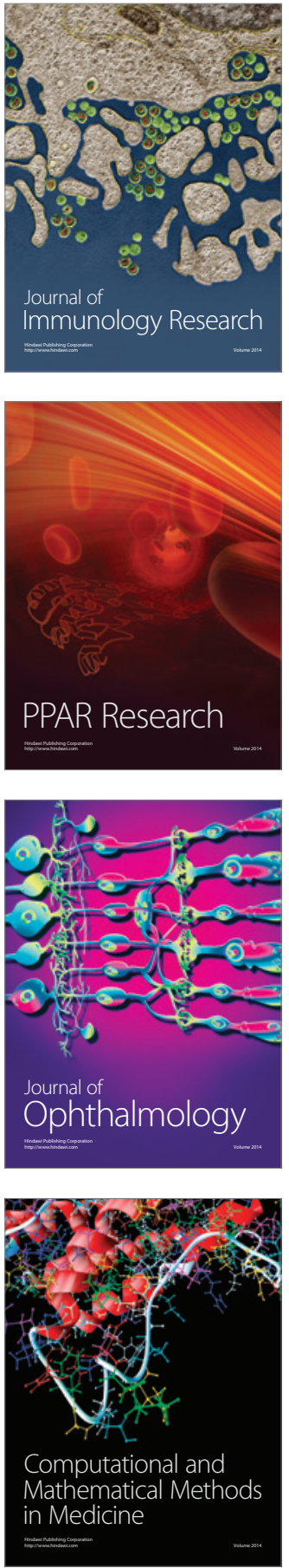

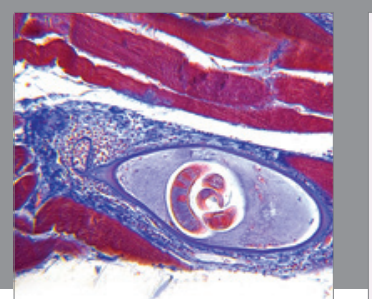

Gastroenterology Research and Practice

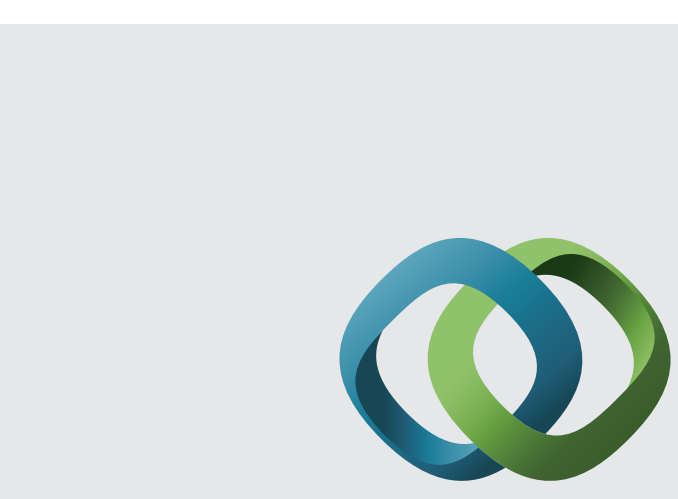

\section{Hindawi}

Submit your manuscripts at

http://www.hindawi.com
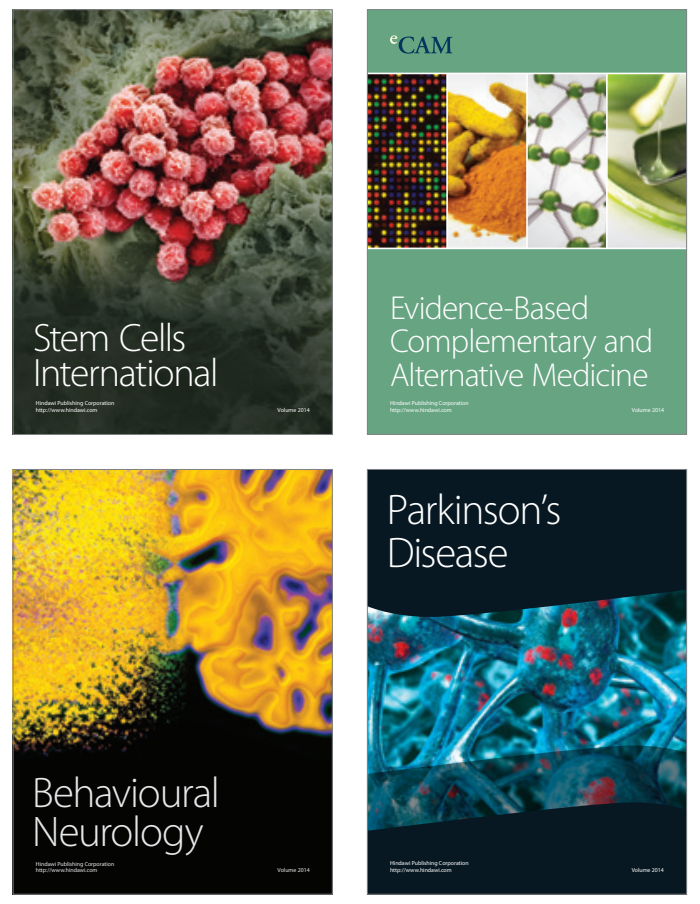
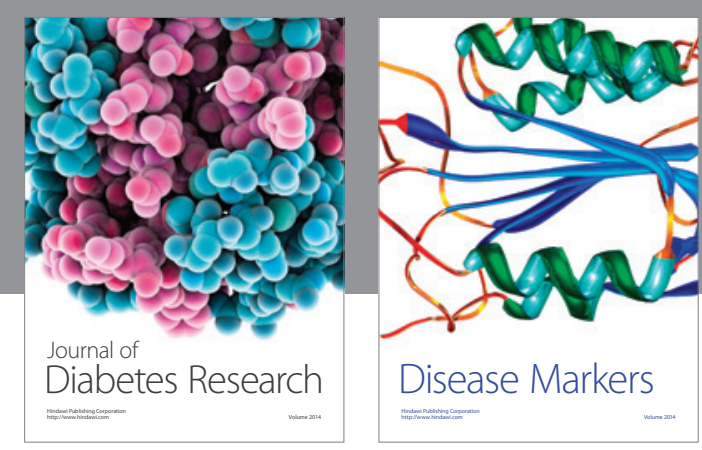

Disease Markers
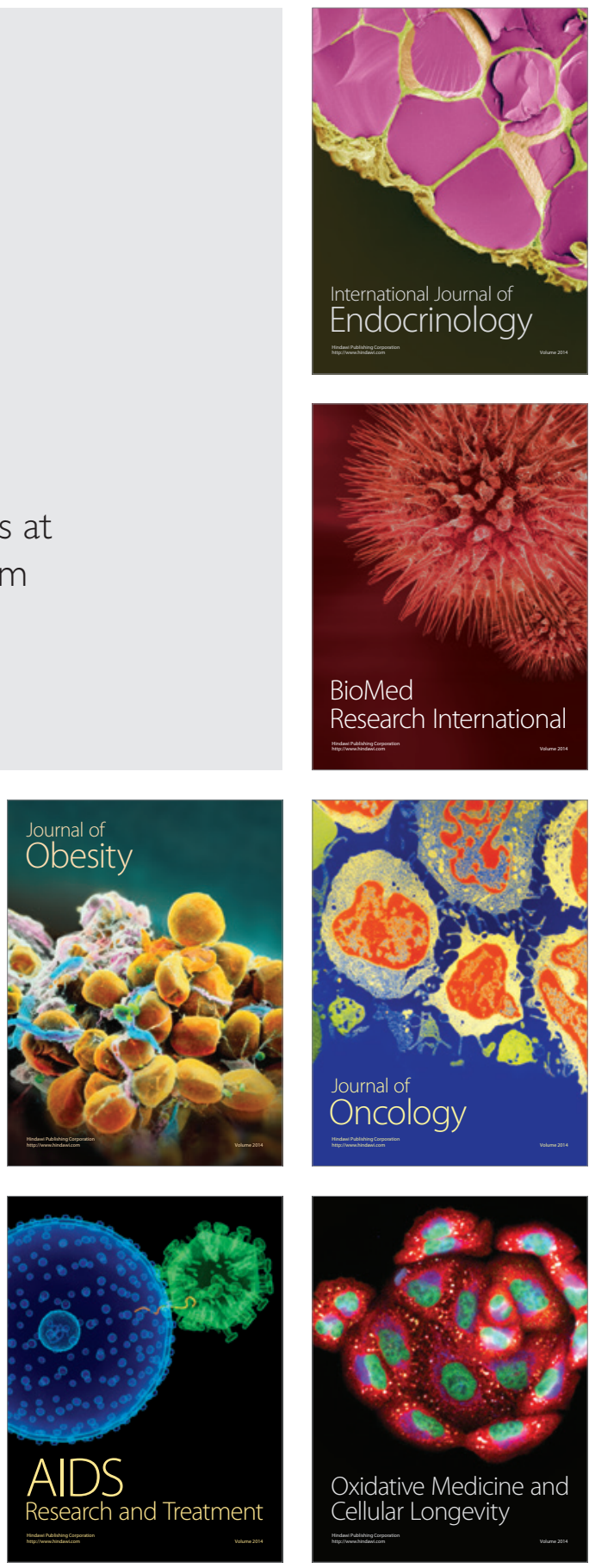